DOI: 10.12731/2070-7568-2018-4-49-62

УДК 351.72

\title{
ВОЗМОЖНОСТИ РАЗВИТИЯ \\ ГОСУДАРСТВЕННО-ЧАСТНОГО ПАРТНЕРСТВА ВОЛГОГРАДСКОЙ ОБЛАСТИ В ЦЕЛЯХ РЕАЛИЗАЦИИ ИНФРАСТРУКТУРНЫХ ПРОЕКТОВ
}

\section{Иванов В.Ю.}

Технологическое отставание в развитии некоторых секторов экономики и недостаточное развитие инфраструктуры является одним из вызовов в призме ограничения внутренних факторов роста, требующих финансовых вложений. Ограничение финансовых возможностей бюджетов всех уровней и наличие потенциала у частного сектора подчеркивают объективную возможность интеграции через механизм государственно-частного партнерства для реализации инфраструктурных проектов. Государственночастное партнерство позволяет обеспечить дополнительные источники финансирования инфраструктурных объектов.

Особое внимание уделено опыту реализации инфраструктурных проектов на территории Волгоградской области: представлены лучшие практики реализации таких проектов, преимущественно в форме концессий, выделены стратегические приоритеты развития ГЧП.

Для оченки потенциала привлечения инвестиций для реализациии проектов был проведен анализ и определен уровень развития ГЧП в регионе по методике оченки факторов. Информацией для исследования стали систематизированные данные Национального Центра государственно-частного партнерства. Развитию ГЧП в регионе способствует системная работа по наведению порядка во всех сферах, созданию условий для привлечения инвесторов, которая ведется с 2014 года. За это время количество проектов, реализуемых в рамках государственно-частного партнерства, увеличилось с двух до тринадияати. Одним из самых успешных примеров является кониессионное соглашение между администрацией 
Волгограда и ООО «Кониессии водоснабжения», подписанное в 2015 году и ставшее крупнейшим в Европе. Опьт вошел в сборник лучиих российских практик в сфере ЖКХ.

Цель - изучить возможности развития государственно-частного партнерства Волгоградской области в целях реализации инфраструктурных проектов.

Метод или методология проведения работы: методология исследования представлена сравнительным анализом, синтезом, табличным методом обработки и представления данных.

Результаты: механизм государственно-частного партнерства должен стать ключевым фактором реформирования системы государственного управления, новой концепщией отношений государства и бизнеса. Анализ и оиенка уровня развития государственночастного партнерства в рассматриваемом регионе подтвердил возрастающий потенцииал привлечения инвестищчй для реализациии инфраструктурных проектов.

Область применения результатов: полученные результаты целесообразно рекомендовать органам государственной власти при разработке программ по созданию условий для развития государственно-частного партнерства в цеелях реализации инфраструктурных проектов.

Ключевые слова: инфраструктурные проекты; инфраструктура; государственно-частное партнёрство; кониессия; развитие; регион.

\section{POSSIBILITIES OF DEVELOPMENT OF PUBLIC-PRIVATE PARTNERSHIP OF THE VOLGOGRAD REGION FOR IMPLEMENTATION OF INFRASTRUCTURE PROJECTS}

\section{Ivanov V.Yu.}

The technological underdevelopment of some economic sectors and the lack of infrastructure development is one of the challenges in terms of limiting internal growth factors that require financial investment. 
The limited financial possibilities of budgets of various levels and potential capacity of the private sector emphasize the balanced possibility of integration through the mechanism of public-private partnership for infrastructure projects implementation. Public-private partnership provides additional sources of financing into infrastructure facilities.

Special attention is paid to experience of implementation of infrastructure projects in the territory of the Volgograd region: the best practices of implementation of such projects, mainly in the form of concessions are presented, strategic priorities of development of PPP are allocated.

For assessment of potential of attraction of investments for implementation of projects the analysis was carried out and the level of development of PPP in the region is determined by a technique of assessment of factors. The systematized data of the National Center of public-private partnership became information for a research. System work on establishing order in all spheres, to creation of conditions for attracting investors which is conducted since 2014 contributes to the development of PPP in the region. During this time the number of the projects implemented within public-private partnership increased from two to thirteen. One of the most successful examples is the concession agreement between administration of Volgograd and LLC Kontsessii vodosnabzheniya signed in 2015 and which became to the largest in Europe. Experience was included into the collection by the best Russian the practician in housing sector.

Purpose: to study possibilities of development of public-private partnership of the Volgograd region for implementation of infrastructure projects.

Methodology: the research methodology is presented by comparative analysis, synthesis, tabular method of data processing and presentation

Results: the mechanism of public-private partnership is meant to be a key factor in reforming the system of public administration, a new concept of relations between the state and business. The analysis and estimation of the level of development of public-private partnership in the region under consideration has confirmed the increasing potential of attracting investments for the implementation of infrastructure projects

Practical implications: it is advisable to recommend the obtained results to the governmental authorities in the development of programs on 
creation of conditions for the development of public-private partnership for the implementation of infrastructure projects

Keywords: infrastructure projects; infrastructure; public-private partnership; BOT project; development; region.

\section{Введение}

Конкретные шаги по дальнейшему социально-экономическому развитию страны и регионов, в том числе инфраструктурному, требуют своевременных бюджетных вложений, зачастую масштабных. Условия ограниченного финансирования со стороны государства поднимают вопрос об оптимальности реализации инфраструктурных проектов в формате государственно-частного партнерства (далее - ГЧП). Сама суть ГЧП сводится к отношениям по привлечению частных структур к реализации проектов. Государство должно выступать инициаторов и координатором таких решений.

Под инфраструктурнылм проектом в рамках исследования будем понимать комплекс взаимосвязанных и последовательных действий, в результате которых при заданных ограничениях временного и финансового характера, а также требований к качеству поставленных результатов, достигаются поставленные цели (создание, модернизация или расширение объектов инфраструктуры).

Вопросами специфики реализации инфраструктурных проектов занимаются такие авторы как Т.А Головина, О.И. Гулакова, С.С. Елецкая, С.А. Измалкова, М.С.Попов, Л.Д. Сангинова, И.А. Тронина, И.Л. Фаустова и др.[9,11,12,17]. Проблемы организации и развития государственно-частного партнерства изучает Варнавский В.Г. $[1,2]$. Информационно-эмпирическая базу исследования представлена материалами официального ресурса по государственно-частному партнерству «Платформа поддержки инфраструктурных проектов «Росинфра», аналитическими данными Национального Центра государственно-частного партнерства $[7,8,10]$.

Цель - изучить возможности развития государственно-частного партнерства Волгоградской области в целях реализации инфраструктурных проектов. 
Достижение поставленной цели предопределило решение следующих задач: 1) обосновать необходимость развития государственночастного партнерства для реализации инфраструктурных проектов; 2) проанализировать имеющийся потенциал Волгоградской области в контексте создания условий в целях развития государственночастного партнерства для реализации инфраструктурных проектов; 3) выявить проблемы развития государственно-частного партнерства в регионе и предложить пути их решения.

\section{Опыт реализации инфраструктурных проектов в форме государственно-частного партнёрства}

\section{на территории Волгоградской области}

Уровень развития государственно-частного партнёрства в регионе за 2013-2017 гг. предопределен возможностью создания условий для привлечения частных инвестиций, которые в свою очередь зависят от триады факторов: развитие институциональной среды в сфере ГЧП, опыт реализации проектов ГЧП, инвестиционная привлекательность региона. С 2015 года в отдельный компонент при определении значения показателя «Уровень развития сферы государственно-частного партнерства в субъекте Российской Федерации» было выделено нормативно-правовое обеспечение сферы ГЧП.

Оценка данных факторов легла в основу методики расчёта рейтинга регионов для определения значения показателя «Уровень развития сферы государственно-частного партнёрства в субъекте Российской Федерации», разработанной Национальным Центром государственно-частного партнерства.

Классификация субъектов Российской Федерации осуществляется по следующим категориям: регионы лидеры (показатель 60-75\%); регионы с высоким потенциалом (показатель 45-60\%); регионы со средним потенциалом (показатель 35-45\%); регионы с низким потенциалом (показатель 25-35\%); регионы с очень низким потенциалом (показатель 0-25\%) [7]. Имеющиеся данные, представленные в исследованиях Центра развития ГЧП, позволили систематизировать показатели развития ГЧП на территории Волгоградской области (таблица 1). 
Таблицуа 1.

Показатели уровня развития ГЧП на территории Волгоградской области*

\begin{tabular}{|l|c|c|c|c|c|}
\hline Под & $\mathbf{2 0 1 3}$ & $\mathbf{2 0 1 4}$ & $\mathbf{2 0 1 5}$ & $\mathbf{2 0 1 6}$ & $\mathbf{2 0 1 7}$ \\
\hline $\begin{array}{l}\text { Итоговый интегральный показатель рейтинга } \\
\text { Волгоградской области по развитию } \\
\text { ГЧП-потенциала, \% }\end{array}$ & 40,5 & 31,3 & 33,9 & 42,0 & 50,3 \\
\hline $\begin{array}{l}\text { Изменение интегрального показателя } \\
\text { рейтинга Астраханской области по развитию } \\
\text { ГЧП-потенциала }\end{array}$ & & $-9,2$ & $+2,6$ & $+8,1$ & $+8,3$ \\
\hline $\begin{array}{l}\text { Позиция в рейтинге субъектов по развитию } \\
\text { ГЧП-потенциала }\end{array}$ & 30 & 48 & 19 & 37 & 34 \\
\hline Изменение позиции в рейтинге & & -18 & +21 & -18 & -3 \\
\hline
\end{tabular}

Анализ оценки влияния факторов на уровень развития ГЧП в целях реализации инфраструктурных проектов определил Волгоградскую область в 2013 году к региону со средним потенциалом (показатель 35-45\%), заняв 30 позицию их 83 регионов.

Как правило, регионы, вошедшие в эту категорию, характеризуются созданием слаженных условий для развития механизмов ГЧП, и проекты находятся на прединвестиционной стадии (например, проект «Строительство западного обхода г. Волгограда»).

За 2014 год регион ухудшил свои позиции в рейтинге, опустившись на 18 пунктов (с 48 места на 30). Условия для привлечения частных инвесторов продолжают создаваться, однако уровень инвестиционной привлекательности региона по-прежнему низкий $[4,7]$

С развитием концессионного законодательства усовершенствовалась процедура подготовки и заключения концессий. Стало возможным распространение платы концедента на все объекты, что впоследствии нашло отражение в ряде социально значимых проектов Волгоградской области. Эти обстоятельства стали значимыми для развития ГЧП и в 2015 году произошло повышение рейтинга рассматриваемого региона (улучшил свои позиции, поднявшись с 48 на 19 место) [7].

Первым примером финансирования концессионного проекта в отрасли ЖКХ (в частности, водопроводно-канализационного хозяйства) через облигационный выпуск и самым крупным в 2015 году 
муниципальным проектом ГЧП в России общим объемом инвестиций более 58 млрд руб стал проект «Реконструкция и модернизация системы водоснабжения и водоотведения г. Волгограда [7].

Также 2 проекта Волгограда за 2017 год вошли в топ-10 концессионных проектов (по общему объему инвестиций) с участием институциональных инвесторов [4]. Концессионное соглашение в отношении системы коммунальной инфраструктуры - МУП «Горводоканал» г. Волгограда это проект модернизации централизованной системы холодного водоснабжения и водоотведения, обновления коммунальной инфраструктуры, повышения качества и надежности поставки ресурсов на основе концессионной модели. Срок реализации проекта - 30 лет, общий объем инвестиций 58000000 тыс.руб. Проект признан передовым опытом и одним из лучших в Европе; его практика зафиксирована в сборнике лучших в сфере ЖКХ в России и внедряется в Камчатском крае, Ульяновской области, Республике Бурятия и Удмуртской Республике. Второй проект - это Концессионное соглашение в отношении системы теплоснабжения г. Волгограда (сфера реализации коммунально-энергетическая). Срок реализации проекта - 30 лет, общий объем инвестиций 29600000 тыс.руб.

Признавая экономическую эффективность передачи объектов коммунальной инфраструктуры в концессию, практика заключения проектов ГЧП региона распространяется и на сферу благоустройства - обустройство набережных, общественных пространств, парков [10]. Так, 6 июня 2017 года было подписано концессионное соглашение между Администрацией города Волгограда и ООО «Парк» о создании «Центрального парка культуры и отдыха» (ЦПКиО) в Волгограде. В ходе реализации значимого инфраструктурного проекта в форме концессии на месте заброшенного парка появится уникальный рекреационный объект, что послужит импульсом к развитию туристической инфраструктуры Волгограда и укреплению экономического потенциала региона в целом. Возрождение парка приведет к созданию новых рабочих мест и обеспечит заказами представителей малого и среднего бизнеса региона, будет способствовать повышению налоговых отчислений в бюджет. Сумма ин- 
вестиций, направленных на модернизацию парковой зоны, составит порядка 330 млн. руб. Срок действия соглашения - 39 лет.

Основным фактором привлекательности такого проекта - возможность реализации полностью за счет внебюджетных источников и применения коммерческой модели возврата инвестиций.

В общероссийском рейтинге за 2017 год Волгоградская область улучшила свои позиции на три пункта и заняла $34-е$ место из 85 . В Южном федеральном округе регион стал одним из лидеров.

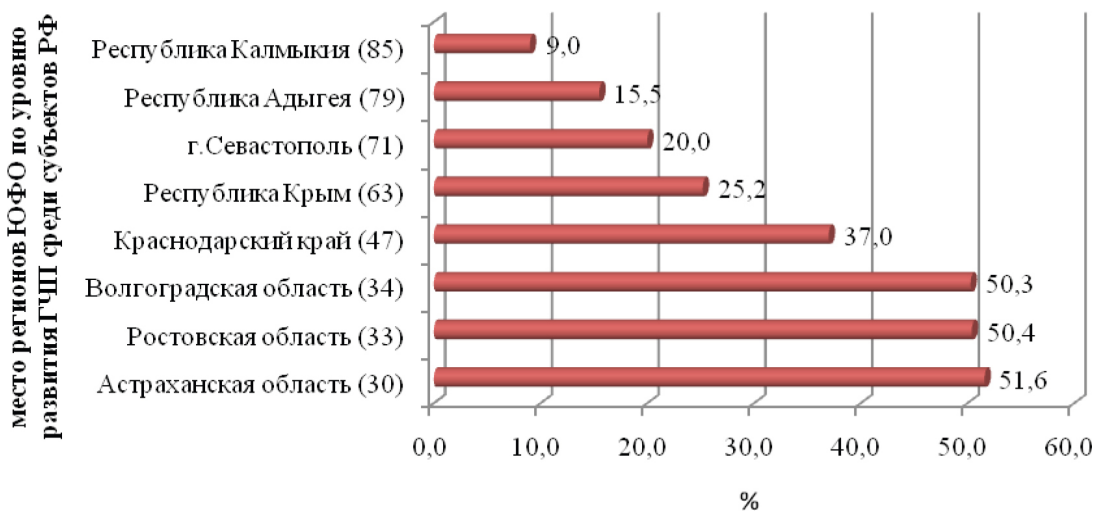

Рис. 1. Рейтинг регионов России по уровню развития ГЧП за 2017 г. [7]

От региона для участия в федеральном конкурсе было направлено 13 проектов, в числе которых концессионные соглашения по благоустройству центрального парка культуры и отдыха, реконструкция санаторного комплекса на озере Эльтон, открытие диагностической лаборатории и другие. Модернизация теплового хозяйства Волгограда с октября 2016 года ведется также в рамках ГЧП. Благодаря привлечению в отрасль теплоснабжения средств инвесторов в рамках концессионных соглашений, финансирование работ по подготовке к осенне-зимнему периоду в 1,4 раза выше. В 2018 году заключено концессионное соглашение в отношении объектов наружного освещения Волгограда. В 2018 году заключено концессионное соглашение в отношении объектов наружного освещения Волгограда [3]. По данным Национального Центра ГЧП, на стадии подписания согла- 
шений находятся проект региона: «Создание спортивного комплекса и центра дополнительного образования в Волгоградской области». Объем частных инвестиций 40000 тыс. руб. В топ-20 крупнейших инфраструктурных проектов, планируемых к реализации за счет средств бюджета, в том числе вне государственных программ отнесен проект региона: Строительство и реконструкция автомобильной дороги М-21 Волгоград - Каменск-Шахтинский до границы с Украиной (на Днепр (быв. Днепропетровск), Кишинев). Реконструкция автомобильной дороги А-260 Волгоград - Каменск-Шахтинский граница с Украиной км 11+000 - км 24+500, Волгоградская область. Бюджетное финансирование составит 5 706,58 млн руб [7].

\section{Заключение}

Признавая необходимость привлечения инвестиций для реализации инфраструктурных, с 2014 года на территории Волгоградской области ведется системная работа по наведению порядка во всех сферах, созданию условий для привлечения инвесторов. За это время количество проектов, реализуемых в рамках государственночастного партнерства, увеличилось с двух до тринадцати.

В статье проанализированы возможности развития государственно-частного партнерства Волгоградской области в целях реализации инфраструктурных проектов. Изучение институциональной среды и нормативно-правовой базы ГЧП в регионе (на основе систематизированных данных, представленных Национальным Центром государственно-частного партнерства) позволило выделить компоненты, способствующие созданию таких условий. К ним относятся: наличие специалистов, имеющих соответствующую квалификацию в сфере ГЧП, наличие специализированного информационного ресурса региона в сфере ГЧП в информационно-телекоммуникационной сети Интернет или раздела на официальном сайте региона, органа власти (уполномоченного органа) или инвестиционном портале субъекта Российской Федерации, наличие в открытом доступе перечня объектов, в отношении которых планируется заключение соглашений о ГЧП, концессионных соглашений. 
Целесообразно продолжать расширение налоговых льгот и иных мер поддержки частных партнеров, поскольку основа этого компонента присутствует в регионе и является, на наш взгляд, одним из инструментов повышения инвестиционной привлекательности территории [10].

Так, результаты рейтинга с одной стороны упрощают для частного инвестора процедуру выбора региона для реализации проекта ГЧП, с другой - стимулируют региональные администрации совершенствовать институциональную среду в сфере ГЧП и накапливать опыт реализации ГЧП-проектов. Следует выделить компоненты, присутствующие в регионе и нуждающиеся в модернизации их деятельности и назначении. Это наличие уполномоченного органа в сфере ГЧП, в том числе концессионных соглашений и специализированной структуры, ответственной за сопровождение проектов ГЧП.

Существенным недостатком, определяющим уровень развития ГЧП в регионе, а соответственно процесс привлечения инвестиций, является отсутствие межведомственного органа, ответственного за рассмотрение инициируемых проектов ГЧП и выработку политики в сфере ГЧП. Поэтому возникает вопрос о необходимости его создания для успешной реализации проектов ГЧП, что позволит повысить уровень социально-экономического развития.

\section{Список литературы}

1. Варнавский В.Г. Государственно-частное партнерство: некоторые вопросы теории и практики // Мировая экономика и международные отношения. 2011. № 9. С. 41-50.

2. Варнавский В.Г. Управление государственно-частными партнерствами за рубежом // Вопросы государственного и муниципального управления. 2012. № 2. С. 134-147.

3. Волгоградская область - в тройке лидеров регионов ЮФО по уровню развития государственно-частного партнерства. URL: http:// economics.volgograd.ru/current-activity/cooperation/news/184848/

4. Государственно-частное партнерство в России 2017-2018: текущее состояние и тренды, рейтинг регионов. V Инфраструктурный конгресс «Российская неделя ГЧП». URL: http://www.p3week.ru 
5. Крекотнев Р.Н. Государственно-частное партнерство: экономическая природа и принципы применения // Проблемы экономики и управления нефтегазовым комплексом. 2015. № 1. С. 21-27.

6. Мошкова Л.Е. Взаимодействие бизнеса и власти: оценка возможности применения зарубежного опыта в российских условиях // Вестник Тверского государственного университета. Серия: Экономика и управление. 2014. № 3. С. 50-58.

7. Национальный Центр государственно-частного партнерства. URL: http://pppcenter.ru/

8. Официальный ресурс по государственно-частному партнерству «Платформа поддержки инфраструктурных проектов «Росинфра» URL: http://www.pppi.ru/content/o-proekte

9. Попов М.С. Понятие инфраструктурных проектов и специфика их правовой природы // Труды Института государства и права Российской академии наук. 2015. № 6. С. 50-60.

10. Проект национального доклада о привлечении частных инвестиций в развитие инфраструктуры и применении механизмов государственночастного партнерства в Российской Федерации Рейтинг регионов России по уровню развития государственно-частного партнерства 2017-2018. М.: Центр развития государственно-частного партнерства. 2018. 80 с.

11. Ременцов А.А. Развитие транспортной инфраструктуры Российской Федерации на принципах государственно-частного партнерства // Автотранспортное предприятие. М., 2015. №9 С. 30-34.

12. Управление инфраструктурными проектами: учебное пособие для высшего профессионального образования / С.А. Измалкова, Т.А. Головина, И.Л. Фаустова, И.А. Тронина, С.С. Елецкая. Орел: ФГБОУ ВПО «Госуниверситет УНПК», 2012. 171 с.

13. Altshuler A. Mega-Projects: The Changing Politics of Urban Public Investment / A. Altshuler, D. Luberoff. Washington, DC : Brookings Institution, 2003. 471 p.

14. Andrew K. Rose and Mark M. Spiegel, The Olympic Effect // National Bureau of Economic Research. 2009. №12, pp. 11-20.

15. Burton R. Consider Intangibles When Weighing Olympic Host City Benefits // Sports Business Journal. 2009. №2. 
16. Implementation of Mega-Projects for the Development of Problematic Territories of Siberia and Ural of Russia / I.V. Mitrofanova, A.N. Zhukov, V.V. Batmanova, I.A. Mitrofanova // Mediterranean Journal of Social Sciences. 2015. Vol. 6, № 3, suppl.1, pp. 575-580.

17. Mitrofanova Inna V., Russkova Elena G., Batmanova Victoria V., Shkarupa Ekaterina A. Drivers of the Regional Economic Growth and the Problem of "White Elephants" of the Russian Olympic Megaproject "Sochi 2014" // Mediterranean Journal of Social Sciences. Vol. 6, no. 4, Supplement 2, July 2015, pp. 267-277 (Scopus Database). Doi: 10.5901/mjss.2015.v6n4s2p

\section{References}

1. Varnavskij V.G. Gosudarstvenno-chastnoe partnerstvo: nekotorye voprosy teorii i praktiki [Public-private partnership: some questions of the theory and practice]. Mirovaya ehkonomika i mezhdunarodnye otnosheniya [World economy and international relations], 2011, no.9, pp. 41-50.

2. Varnavskij V.G. Upravlenie gosudarstvenno-chastnymi partnerstvami za rubezhom [Management of public-private partnerships abroad]. Voprosy gosudarstvennogo i municipal'nogo upravleniya [Questions of the public and municipal administration], 2012, no.2, pp. 134-147.

3. Volgogradskaya oblast $-v$ trojke liderov regionov Yuzhnogo Federal 'nogo okruga po urovnyu razvitiya gosudarstvenno-chastnogo partnerstva [The Volgograd region - in top three of regions of the Southern Federal District on the level of development of public-private partnership]. http:// economics.volgograd.ru/current-activity/cooperation/news/184848/

4. Gosudarstvenno-chastnoe partnerstvo v Rossii 2017-2018: tekushhee sostoyanie i trendy’, rejting regionov. V Infrastrukturny j kongress «Rossijskaya nedelya gosudarstvenno-chastnogo partnerstva» [Public-private partnership in Russia 2017-2018: current state and trends, rating of regions. The V Infrastructure congress "Russian Week of Public-private Partnership"]. http://www.p3week.ru

5. Krekotnev R.N. Gosudarstvenno-chastnoe partnerstvo: ehkonomicheskaya priroda i principy primeneniya [Public-private partnership: economic nature and principles of application]. Problemy ehkonomiki i upravleniya neftegazovym kompleksom [Problems of economy and management of an oil and gas complex], 2015, no.1, pp. 21-27. 
6. Moshkova L.E. Vzaimodejstvie biznesa i vlasti: ocenka vozmozhnosti primeneniya zarubezhnogo opyta $\mathrm{v}$ rossijskih usloviyah [Interaction of business and power: assessment of a possibility of application of foreign experience in the Russian conditions]. Vestnik Tverskogo gosudarstvennogo universiteta. Seriya: EHkonomika i upravlenie [Bulletin of Tver State University. Series: Economy and management], 2014, no.3, pp. 50-58.

7. Nacional `ny j Centr gosudarstvenno-chastnogo partnerstva [National Center of public-private partnership]. http://pppcenter.ru/

8. Oficial 'ny j resurs po gosudarstvenno-chastnomu partnerstvu «Platforma podderzhki infrastrukturny 'x proektov «Rosinfra» [Official resource on public-private partnership "The platform of support of the infrastructure Rosinfra projects]. http://www.pppi.ru/content/o-proekte

9. Popov M.S Ponyatie infrastrukturny'x proektov i specifika ix pravovoj prirody` [Concept of infrastructure projects and specifics of their legal nature]. Trudy`Instituta gosudarstva i prava Rossijskoj akademii nauk [Works of Institute of the state and right of the Russian Academy of Sciences], 2015, no 6, pp. 50-60.

10. Proekt nacional 'nogo doklada o privlechenii chastny $x$ investicij $v$ razvitie infrastruktury $i$ primenenii mexanizmov gosudarstvenno-chastnogo partnerstva v Rossijskoj Federacii Rejting regionov Rossii po urovnyu razvitiya gosudarstvenno-chastnogo partnerstva 2017-2018 [The draft of the national report on attraction of private investments into development of infrastructure and use of mechanisms of public-private partnership in the Russian Federation the Rating of regions of Russia on the level of development of public-private partnership of 2017-2018]. Moskva / Centr razvitiya gosudarstvenno-chastnogo partnerstva. Publ., 2018. 80 p.

11. Remenczov A.A. Razvitie transportnoj infrastruktury` Rossijskoj Federacii na principax gosudarstvenno-chastnogo partnerstva [Razvitie transportnoj infrastruktury` Rossijskoj Federacii na principax gosudarstvenno-chastnogo partnerstva]. Avtotransportnoe predpriyatie [Motor transportation enterprise], 2015, no 9, pp. 10-34.

12. Izmalkova S.A., Golovina T.A., Faustova I.L., Tronina I.A., Eleczkaya S.S. Upravlenie infrastrukturny 'mi proektami: uchebnoe posobie dlya vy sshego professional nogo obrazovaniya [Management of infrastructure projects: manual for higher education]. Orel, 2012. $171 \mathrm{p}$. 
13. Altshuler A. Mega-Projects: The Changing Politics of Urban Public Investment / A. Altshuler, D. Luberoff. Washington, DC: Brookings Institution, 2003. $471 \mathrm{p}$.

14. Andrew K. Rose and Mark M. Spiegel, The Olympic Effect. National Bureau of Economic Research. 2009. no. 12, pp. 11-20.

15. Burton R. Consider Intangibles When Weighing Olympic Host City Benefits. Sports Business Journal. 2009. no. 2.

16. Implementation of Mega-Projects for the Development of Problematic Territories of Siberia and Ural of Russia / I.V. Mitrofanova, A.N. Zhukov, V.V. Batmanova, I.A. Mitrofanova. Mediterranean Journal of Social Sciences. 2015. Vol. 6, no. 3, suppl.1, pp. 575-580.

17. Mitrofanova Inna V., Russkova Elena G., Batmanova Victoria V., Shkarupa Ekaterina A. Drivers of the Regional Economic Growth and the Problem of "White Elephants" of the Russian Olympic Megaproject "Sochi 2014". Mediterranean Journal of Social Sciences. Vol. 6, no. 4, Supplement 2, July 2015, pp. 267-277 (Scopus Database). Doi: 10.5901/mjss.2015.v6n4s2p

\section{ДАННЫЕ ОБ АВТОРЕ}

Иванов Владимир Юрьевич, доцент кафедры «Экономика, менеджмент и маркетинг», кандидат экономических наук, доцент Рязанский институт (филиал) Федерального государственного бюджетного образовательного учреждения высшего образования «Московский политехнический университет» ул. Право-Льгедская, 26/53, г. Рязань, 390000, Российская Федерация ivu.iwanow@yandex.ru

\section{DATA ABOUT THE AUTHOR}

Ivanov Vladimir Yuryevich, Associate Professor «Economy, Management and Marketing», Candidate of Economic Sciences Moscow Polytechnic University, Ryazan institute (branch) 26/53, Pravo-Lybedskaya St., 390000, Russian Federation ivu.iwanow@yandex.ru SPIN-code: 80799555 ORCID: 0000-0002-3486-4937 